\title{
The Dar es Salaam Seascape: A Case Study of an Environmental Management 'Hotspot'
}

\author{
Greg M. Wagner \\ Faculty of Aquatic Sciences and Technology, University of Dar es Salaam, P.O. Box 35064, Dar es Salaam, \\ Tanzania
}

\begin{abstract}
Key words: Dar es Salaam seascape, Driver-Pressure-State-Impact-Response analysis, environmental management
\end{abstract}

\begin{abstract}
The Dar es Salaam seascape contains a variety of interacting coastal and marine ecosystems that support diverse resources, upon which human life has depended for centuries. This paper applies the UNEP Human-Environment Interaction Analytical Approach to examine the changes that have taken place in this seascape over the past few decades. The main drivers of change have been rapid population growth, poverty and inadequate education, together with global climate change. The main pressures have been destructive fishing practices, mangrove harvesting, overfishing, tourism infrastructure and polluting emissions. These pressures have resulted in substantial negative environmental state changes, e.g., habitat loss and degradation, biodiversity loss and disturbance of food webs, and coastal erosion/accretion. Thus, the Dar es Salaam seascape has become an environmental "hotspot" of degradation, with consequent negative impacts on human well-being such as loss of livelihoods and reduction in the availability of food, building materials and firewood.

Since the early 1990s, responses or interventions by government bodies, NGOs and integrated coastal management programmes, operating at the national level and at localized levels, have targeted only limited areas of the seascape. Despite these management efforts, there are many critical outstanding and emerging issues that remain unresolved. The paper concludes that it is not effective to manage the seascape in a "piecemeal" fashion and recommends that an integrated coastal management programme should be established to cover the entire Dar es Salaam seascape.
\end{abstract}

\section{INTRODUCTION}

Dar es Salaam City now covers the entire area of Dar es Salaam Region (Fig. 1), which is 1,393 $\mathrm{km}^{2}$ (United Republic of Tanzania, 1992), with a coastline that is over $100 \mathrm{~km}$ long (Josiah, 1997). Administratively, it is divided into three municipalities: Kinondoni, Ilala and Temeke. The coastal zone of Dar es Salaam is an intricate mosaic of islands fringed by coral reefs, numerous coral patch reefs, estuaries and streams lined with mangrove forests, lagoons with seagrass beds covering large areas and shores comprising sandy beaches, beach rock as well as rock cliffs and platforms (Hartnoll, 1975; Kairu \& Nyandwi, 2000). The coastal waters are dominated by the East African coastal current, which always flows northward (though its speed changes seasonally), conveying plankton (including larvae), nutrients and human-generated pollution. However, various factors related to bathymetry, tidal movements and freshwater stream flow, as well as wavegenerated currents, result in localized eddies and countercurrents that change by the hour. The Dar es 


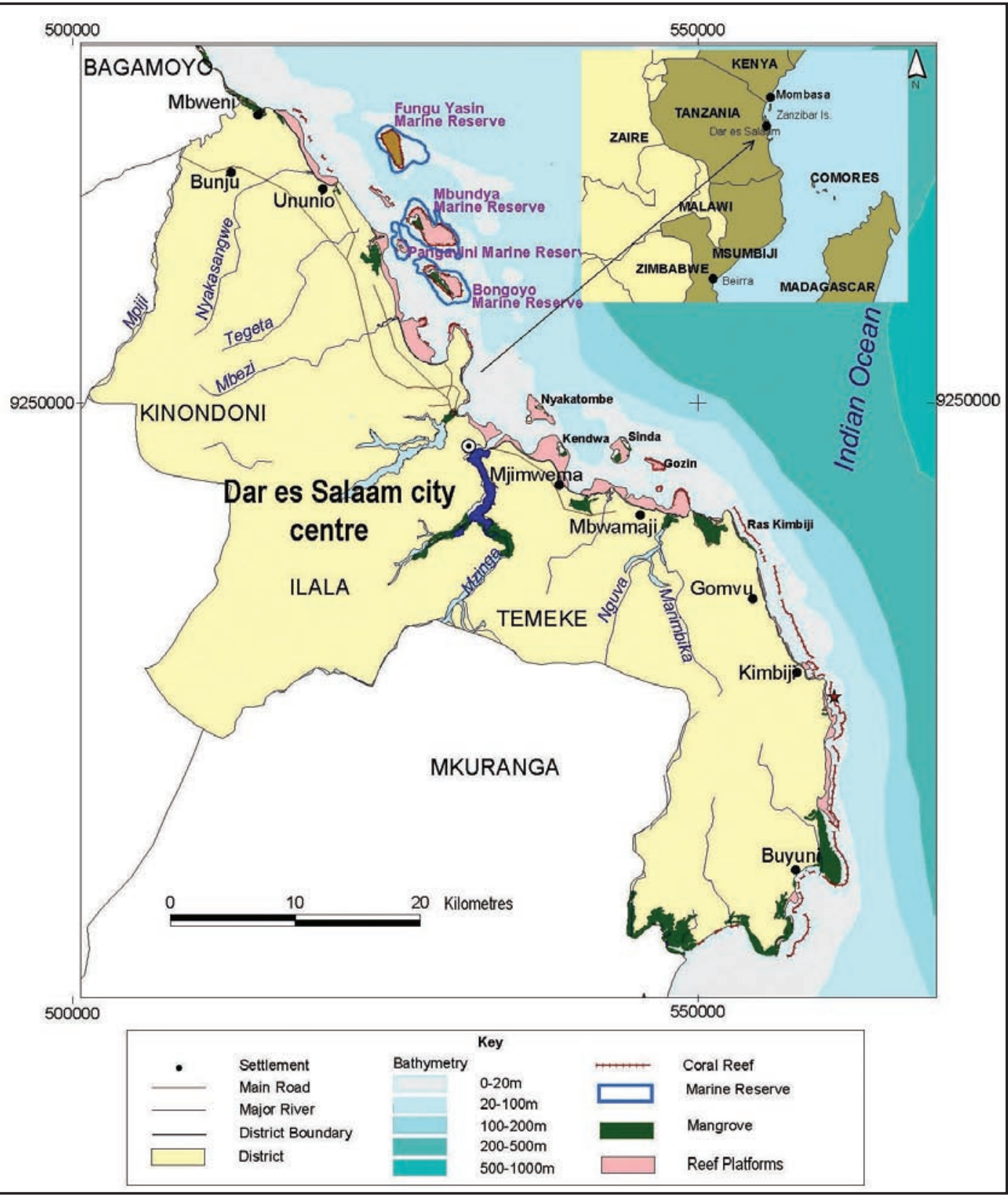

Fig. 1. Map of Dar es Salaam Region showing the location of the Dar es Salaam Marine Reserve System (DMRs)

Salaam seascape supports a rich diversity of marine flora and fauna, upon which human life has been dependent for centuries.

Over the past few decades, the Dar es Salaam seascape has become an environmental 'hotspot', largely due to human population growth and its associated problems of poverty, inadequate education and lack of employment opportunities.
Thus, the seascape has been exposed to a wide variety of serious threats or pressures, most of them anthropogenic, which have led to significant changes in the state of the coastal and marine environment. The main pressures include destructive fishing practices, overfishing, unsustainable mangrove cutting, polluting emissions, unmanaged tourism, 
beach activities and outbreaks of the Crown-ofthorns Starfish.

In this paper, a seascape is considered as an expansive coastal area which forms a network based on connectivity between biological, social and economic factors and in which a wide range of environmental issues and concerns prevail (WWF, 2005). This definition emphasizes the importance of a seascape as a viable unit for environmental management. Ecologically, a seascape includes a network of coastal and marine ecosystems that interact through physical, chemical and biological processes and among which there is exchange of energy, materials and organisms. This network of ecosystems is integrated into an interactive seascape wherein the unifying medium is the water itself, which allows for the movement of fish, invertebrates and other nekton. In addition, the water is continuously moving through the influence of tides, ocean currents and stream flow, carrying plankton, nutrients, sediments and other materials. The various ecosystems provide critical, mutually beneficial ecological services. For example, mangroves filter out sediments from rivers and runoff, which would otherwise be detrimental to the health of seagrass beds and coral reefs; coral reefs protect seagrass beds and mangroves from the severity of open ocean waves.

Management of a coastal area is a process that involves a number of steps that are repeated in a cyclic fashion, including carrying out adequate assessments of the biophysical and human environment as well as relevant management issues; thorough analysis of all variables and their interactions, including cause-and-effect relationships; planning of goals, strategies and activities; implementation of plans; and periodic evaluation, including re-assessment and monitoring of the biophysical and human environment. Effective management requires a collaborative approach, or co-management, along every step of the process. In the case of a seascape, whose components interact and are highly interdependent, attempts at management can only be successful if a seascape approach is taken, i.e., an integrated approach whereby all interacting habitats and socioeconomic factors are considered in a holistic way.

This paper is a case study, which examines the rich endowments found in the Dar es Salaam seascape, and then proceeds with a causal chain analysis of changes that have taken place in the seascape over the past few decades. It goes further to examine the complete cycle of cause-and-effect relationships from society through the environment and back to society. The paper applies the UNEP Human-Environment Interaction Analytical Approach (UNEP, 2006) (Fig. 2), which is built on the Driver-Pressure-State-Impact-Response (DPSIR) Framework (Organisation for Economic Co-operation and Development, 1993). According to this analytical approach, the term 'drivers' refers to the root causes of change. The term 'pressures' is used to refer to those immediate causes of environmental change, usually human activities that directly affect the environment (e.g., destructive fishing practices) or climatedriven marine pressures such as waves and surges. 'State' refers to the state or status of the natural environment. 'Impacts' refers to the impacts on human well being as a result of state changes in ecosystem goods and services available to human populations. 'Responses', most of which can be considered as management interventions, refer to the ways in which governments, nongovernmental organizations, the private sector and local communities react to, or deal with, changes in the state of the environment and their impacts on society.

This paper examines responses to the issues of the Dar es Salaam seascape during two time periods. From about 1970 to the early 1990s, some responses were initiated, but no effective management took place and there was a wide range of severe abuses to the environment taking place, thus exacerbating the 'hotspot' condition of this seascape. From the early 1990s onwards, steps have been taken to establish effective management programmes. Despite these programmes, serious issues remain. The paper concludes with recommendations for improving the management of the Dar es Salaam seascape.

\section{ENDOWMENTS OF THE DAR ES SALAAM SEASCAPE}

Within the Dar es Salaam Seascape (Fig. 1), there are eight uninhabited islands (Mbudya, Pangavini, Bongoyo, Inner and Outer Makatumbe, Kendwa and Inner and Outer Sinda) ranging in length 


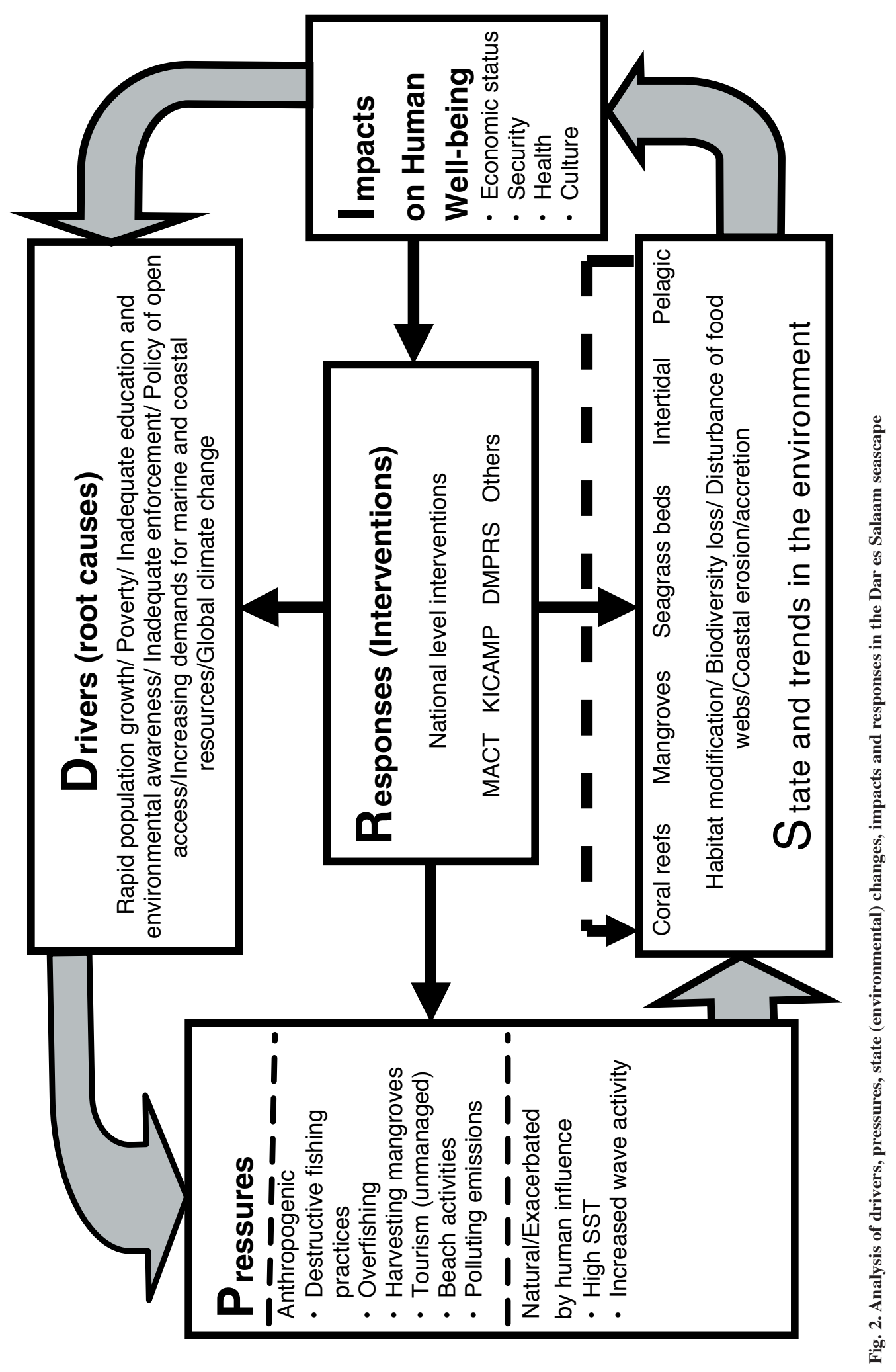


from slightly less than $0.5 \mathrm{~km}$ (Pangavini) to 2.9 $\mathrm{km}$ (Bongoyo). Along most of the coastal area between the islands and the mainland, there is a shallow lagoon with a maximum width of ca. 8 $\mathrm{km}$. Most of the peripheries of these islands are fringed by coral reefs with Mbudya having the largest (Board of Trustees for Marine Parks and Reserves Tanzania, 2005). The first three islands named above are part of the Dar es Salaam Marine Reserves System (DMRS), which also includes a large patch reef known as Fungu Yasini. In addition, the Dar es Salaam seascape includes numerous other patch reefs. Many areas of the fringing and patch reefs have, or at least once had, excellent coral development of high diversity (Hamilton \& Brakel, 1984; Pearson, 1988). Some sections of the mainland coastline are fringed with reefs, though the coral development is generally poor (Pearson, 1988). Hamilton (1975) and Hamilton \& Brakel (1984) reported that the East African region has 140 hard coral species belonging to 55 genera, out of which 88 species belonging to 34 genera are found in the Dar es Salaam area.

The Dar es Salaam seascape includes eleven mangrove forests or forest patches (Fig. 1) covering a total of 2,516 ha (Wang et al., 2002). All eight species of mangrove reported to occur in mainland Tanzania (Semesi, 1991) are found in the seascape, the dominant species being Rhizophora mucronata, Ceriops tagal, Avicennia marina and Sonneratia alba (Semesi, 1991; Akwilapo, 2001; Sallema, 2002; Mgaya et al., 2004). The common benthic macrofauna found in or on mangrove sediments are crabs (Sesarma spp., Uca spp., Dotilla fenestrata and Scylla serrata), gastropods (Cerithidea decollata and Terebralia palustris) and polychaetes (Akwilapo, 2001).

Seagrass beds cover much of the shallow lagoon between the islands and the mainland, though there are no data on actual coverage. There are about 12 species of seagrasses in the coastal waters of which Thalassodendron ciliatum and Syringodium isoetifolium are most widely distributed (Semesi \& Shushu, 1988). Other dominant species found in the area include Cymodocea rotundata, $C$. serrulata, Thalassia hemprichii, Halodule uninervis and $H$. wrightii. Within the DMRS alone there are 1,217 ha of seagrass beds surrounding the four reef-fringed islands down to a depth contour of $10 \mathrm{~m}$ (Muhando,
2004 in Board of Trustees for Marine Parks and Reserves Tanzania, 2005).

Algae thrive on the rock cliffs and platforms, such as at Oyster Bay, grow epiphytically on seagrasses and are abundant on coral reefs. In Tanzania, there are over 300 species of red, green and brown macroalgae or seaweeds (Jaasund, 1976), though there has been no determination of the number of species present in the Dar es Salaam seascape. Using a rapid survey technique, Wagner et al. (2001) reported $26 \%$ algal cover on the seaward side of Mbudya Island and $5 \%$ on the landward side. Using the Line Intercept Transect Method, macroalgae were observed to have $25 \%$ cover on the seaward side of Bongoyo and less than $1 \%$ on the sheltered side (Kaaya, 2004), while, at Kendwa Island, there was $13 \%$ algal cover on the seaward side and $3 \%$ on the sheltered northwest side (Mchome, 2002). Brown algae of the genera Sargassum and Turbinaria are the most common on coral reefs.

Mwaiseje (1973), studying the intertidal zone of sandy/muddy of three shores in Dar es Salaam, reported 129 species of macrofauna, saying that these were "some of the species collected". In a similar study in the same sites, Mlay (2000) reported 144 species. Some of the abundant macrofauna included polychaetes (with a mean of 592 individuals $/ \mathrm{m}^{2}$ at Kunduchi), the crab Dotilla fenestrata (136 individuals $/ \mathrm{m}^{2}$ at Kunduchi) and the bivalve Donax faba, which ranged in density at different shores from 160 to 288 individuals $/ \mathrm{m}^{2}$.

Within the Dar es Salaam seascape, there is one major estuary, Dar es Salaam harbour, and several smaller ones, some of which occur along seasonal streams. Several of these estuaries support mangroves and/or seagrass beds. Apart from the estuaries, where there is muddy or sandy/muddy substrate, the seascape's coastline alternates between beautiful sandy beaches, beach rock and majestic rocky cliffs with fringing rock platforms. The rock cliffs, which are nearly all composed of raised coral limestone, range from $4.3 \mathrm{~m}$ above datum at Leopards Cove, Msasani Bay, to $8.8 \mathrm{~m}$ on the northern side of Oyster Bay (Hartnoll, 1975).

Bryceson (1977) reported 265 taxa of phytoplankton in Dar es Salaam coastal waters. The only extensive study of the zooplankton in Dar es Salaam was that of Okera (1971), who identified 
a very diverse species composition. In the Dar es Salaam seascape, sea turtles and dolphins can be observed (Board of Trustees for Marine Parks and Reserves Tanzania, 2005), particularly in the vicinity of Mbudya Island.

\section{DRIVERS OF CHANGE}

The drivers that have led to state changes in the Dar es Salaam seascape are numerous and complex and are basically socio-economic factors and their dynamics (Fig. 2). In a causal-chain analysis of the loss and modification of marine ecosystems, (i.e., loss of total ecosystem area and/or change in biomass, density or biodiversity) in Tanzania (including those in Dar es Salaam), Francis et al. (2001) concluded that the main drivers or underlying root causes of environmental degradation are:

- poverty and unequal distribution of wealth.

- inadequate awareness amongst resource users.

- lack of general education.

- demographic change - particularly migration to coastal urban centres.

- inadequacy of systematically collected longterm monitoring data.

- lack of integrated policy-making and implementation amongst sectors.

- inadequate involvement of communities in decision-making, abuse of influence and lack of transparency in governmental bodies, inadequate enforcement of laws and regulations, the policy of open access to resources.

- lack of economic alternatives which could relieve pressure on the marine resources.

A comprehensive investigation of socioeconomic aspects and environmental problems in two coastal wards where major Dar es Salaam fishing communities are located, i.e., Kunduchi and Mbweni (Fig. 1), was carried out Wagner et al. (1999). These communities can be considered quite representative or typical of coastal communities in the Dar es Salaam area, where there is strong dependence upon marine and coastal resources. Through structured interviews held with a random sample of 145 residents of these communities, it was found that the villagers considered the main drivers of environmental degradation to be poverty (mentioned by $34 \%$ of the interviewees), lack of enforcement (21\%), lack of equipment and methods for proper resource extraction, which is also related to poverty (20\%), lack of education, awareness and expertise (19\%), overpopulation (10\%), and greediness $(10 \%)$.

One of the overriding drivers, which has lead to the occurrence of many of the other drivers mentioned above, has been the population growth of Dar es Salaam, which has been exponential over the past few decades, rising from 356,286 in 1967 (Josiah, 1997) to 2,497,940 in 2002 (Tanzania Bureau of Statistics, 2002), an astounding increase of sevenfold. While natural population increase has occurred, a major contributor to population rise has been rampant migration to Dar es Salaam, not only from all parts of Tanzania, but also from neighbouring countries. According to the 2002 Census, only about half of Dar es Salaam residents $(1,233,531)$ had been born in Dar es Salaam. Similarly, interviews with coastal residents living in Kunduchi and Mbweni wards in Dar es Salaam (Wagner et al., 1999) showed that about one-third of those interviewed had resided there for less than 10 years and about half had resided there for less than 20 years. Large-scale migration has resulted in vast numbers of people moving to Dar es Salaam, often without any concrete plans of how they will support themselves and their families.

This rapid population growth has contributed to the occurrence of a second major driver of change, namely, poverty. In Mbweni and Kunduchi, most interviewees $(79 \%)$ said their income was less than US $\$ 600$ per year and $61 \%$ said that their real income (in terms of purchasing power) had dropped over the past 5 years (Wagner et al., 1999). When asked regarding household size categories, the highest number of interviewees (39\%) said there were 4-6 people in their household and 30\% said there were 7 or more. Another study (Chambo, 1997) examined dependency ratio in Kinondoni District amongst women who are self-employed, particularly in business, and found that $68.7 \%$ of the women interviewed had more than 8 dependents, while $16.7 \%$ had $6-8$. Yet, $88.7 \%$ of these women earned less than US \$20 per month. Household size and dependency ratio are factors that contribute greatly to poverty. 
The huge population increase, combined with poverty has made it impossible for the majority of the Dar es Salaam residents to obtain adequate education and environmental awareness. General education, which could have empowered people to find new and diverse means of livelihood and take pressure off the natural resources, is at a very low level. This seems to be particularly true of the coastal communities of Dar es Salaam. Wagner et al. (1999) reported that about one-third of the Kunduchi and Mbweni residents (31\%) had had no formal education at all, $26 \%$ had completed only up to Standard IV, 3\% had completed Standard VII, and only about $2 \%$ had had postprimary education. Women generally had lower literacy and educational levels than men. Thus, inadequate education combined with a rapidly growing population has led to higher numbers of people being dependent upon marine and coastal resources (Wagner et al., 2001). The major sources of income for the coastal communities were petty businesses $(36 \%)$, which were largely related to marine resources, e.g., transporting and selling fish, followed by direct involvement in fishing (22\%) (Wagner et al., 1999). The role of women in the household economy was very high, with $22 \%$ of those interviewed stating that they contribute $100 \%$ to the household economy and $67 \%$ stating that they contribute $50 \%$ or more. Probably due to the low educational level of women, $78 \%$ were involved in petty businesses as the main source of livelihood, many of which depended on marine resources, e.g., trading fisheries products as well as cooking and selling them in small, open restaurants. At the same time, the main occupation for $42 \%$ of the men was fishing, which reached as high as $78 \%$ in some localities such as Ununio (Fig. 1).

While general knowledge about the environment was limited, many of the actual resource users, e.g., fishermen, showed quite good understanding of the impacts of inappropriate resource use patterns, because the use of the sea is their means of survival (Wagner et al., 1999).

Another important driver is the policy of open access to the marine and coastal environment or the 'tragedy of the commons'. The entire marine environment, including the mangrove forests, is the property of the government and therefore cannot belong to any individual. This results in people not caring about the environment, particularly in the case of migrant fishermen who ruthlessly exploit the natural resources, knowing that they can go back to their homes or elsewhere when resources are depleted (Wagner et al., 2001). Thus, marine resource users extract resources by inappropriate means so that they can get maximum gains on the short term, with no regard for the benefits that others will lose or for long-term benefits of future generations.

The various drivers mentioned above are very complex and interactive. For example, while some fishermen are fairly aware of the negative impacts of destructive fishing practices, poverty often drives them to engage in these environmentally unfriendly resource use methods, just so that they can survive for the day, regardless of any consequences for the future. Another example is that, even though some villagers may be aware that cutting mangrove trees leads to environmental degradation, since they cannot afford to buy cement for building, they have no viable alternative but to cut mangroves.

The chain of interacting drivers mentioned above, particularly, growing population, poverty, and inadequate education, have created insatiable demands for various natural resources, including fisheries products, energy (mangrove firewood and charcoal), building materials (mangrove poles and coral limestone) and space for housing, roads and hotels. The need for space has led to mangrove clearing and coastal construction, with its concomitant erosion and sedimentation.

\section{PRESSURES AND ENVIRONMENTAL STATE CHANGES}

Various pressures in the Dar es Salaam seascape have led to destruction of coral reefs, loss of mangrove abundance, disturbance of seagrass beds, pollution of beaches and reduction of water quality.

While drivers are general in nature, i.e., they do not affect specific ecosystems, they lead to a wide diversity of pressures which directly affect particular ecosystems. Since the pressures are best understood in relation to their impacts on ecosystems the environmental state changes and the pressures that have caused them are dealt with together in this section. The main pressures on the 
coastal and marine environment of Dar es Salaam have been anthropogenic and include destructive fishing practices of various types, mangrove harvesting or clear-cutting, overfishing, unmanaged tourism, coastal development, pollution, rampant collection of ornamental corals and shells, coral mining, boat transport and beach activities. There are other pressures which are basically natural processes, though exacerbated by human activities, such as abnormally high sea-surface temperature causing coral bleaching and the changes in wave incidence causing coastal erosion and accretion (Fig. 2).

Many of these pressures have effects on specific ecosystems only, while others, such as pollution, have effects on several or all marine ecosystems. In this section, pressures specific to the keystone ecosystems, i.e., coral reefs, mangrove forests and seagrass beds, are dealt with first, followed by those that have general effects on the marine environment, such as overfishing and pollution.

\section{Coral Reefs}

The causal chain analysis by Francis et al. (2001) revealed that the major pressure causing coral reef degradation has been the use of destructive fishing practices over several decades (Bryceson, 1978), particularly dynamite fishing and dragging seine nets, which destroy the reef habitat. The critical consequences of destructive fishing practices are that they reduce the total habitat space and decrease the variety of microhabitats by simplifying the topography. The most unsustainable destructive practice is dynamite fishing, which was commonplace in Dar es Salaam from the 1960s until 1997 (Horrill et al., 2000; Wagner, 2004a) and which is still continuing at a lower level to the present day. Numerous blasts, each of which kills all life within a radius of 15-20 m (Guard \& Masaiganah, 1997) and turns the reef structure into rubble within a radius of several meters (Wagner, 2004a), occurring every day over a period of about three decades has had severe impacts on the Dar es Salaam reefs. One of the critical aspects of dynamite damage is that coral recruitment onto the resultant small pieces of unstable rubble is almost impossible. Dragging seine nets over reefs causes extensive mechanical damage, particularly breaking branching forms of hard coral. Spear fishing for octopuses and lobsters can also result in the breakage of corals when carelessly done. Though, when done properly, the use of the basket trap is a traditional and environmentally friendly fishing method, however, fishermen often break off colonies of live coral and place them on the traps to hold them down (Peter, 2002).

Boat transport of various types also creates pressures on coral reefs. Anchoring and grounding of small boats on the reefs causes mechanical damage, which, on a cumulative basis, is likely to have caused significant habitat modification (Wagner, 1999). The probable impacts of the large, high-speed boats commuting between Zanzibar and Dar es Salaam are discussed below under pollution. Walking on reefs for the purpose of collecting shells for curio, or octopus and lobster fishing also has widespread and significant impacts (Horrill et al., 2000). While there is no coral mining in most parts of Dar es Salaam, it has been carried out for many years at Kigamboni, where kilns, burning corals to make lime, are located just a few hundred meters south of the Dar es Salaam harbour. Fishermen at Kendwa Island (Fig. 1) stated that coral mining has caused considerable damage to the reefs in the area (Ibengwe, 2003). Effects of the proliferation of sea urchins on coral reefs are discussed below under overfishing, since it is a result of heavy speciesspecific fishing.

While tourism is generally economically beneficial to the country (Andersson, 1998), if unmanaged it may have negative impacts on the environment. Careless snorkelling and SCUBA diving, as well as anchoring and grounding of tourist boats, can cause damage to corals. Moreover, tourist hotels and facilities generally create pollution, which negatively affects the coastal environment. This issue will be discussed further under pollution.

Coral bleaching is the loss of colour in corals due to death of the zooxanthellae, algae that live symbiotically the tissues of coral polyps, which usually results in the death of the corals as well. Higher than normal seawater temperature (and slightly lower salinities) associated with a combination of global warming and the El-Niño of 1998 caused widespread coral bleaching and death in Tanzania and worldwide. Hard coral 
cover in the reefs offshore from Kunduchi in Dar es Salaam dropped from $43.0 \%$ before the El-Niño event (1997/98) to $35.0 \%$ after the event (1999), which was attributed primarily to coral bleaching (Wilkinson, 2004).

Outbreaks of the Crown-of-thorns Starfish (COTs), a notorious predator of corals, are another type of natural pressure that is thought to be sometimes triggered by human influences. Though such outbreaks have not been common in Tanzania, one recently (2004/2005) occurred in the Dar es Salaam area. Kaaya (2004) found a mean density of $1.5 \mathrm{COTs} / 20-\mathrm{m}^{2}$ belt transect on the northern side of Bongoyo Island, with certain patches reaching densities as high as $0.88 \mathrm{COTs} / \mathrm{m}^{2}$. Considerable damage to the reef was observed in this site where there was $25.8 \%$ cover of dead coral, primarily attributed to the COTs attack. About one year later, Hamed (2005) found a mean density of 4.7 COTs $/ 20-\mathrm{m}^{2}$ belt transect in the same site, with dense aggregations in some areas. A survey carried out in 2005 by Marine Parks and Reserves Unit revealed the presence of large numbers of COTs on all four reefs in the DMRS, with counts of up to $10-15 \mathrm{COTs} / \mathrm{m}^{2}$ being observed in some areas (Julius, 2005). Such outbreaks may be related to high nutrient levels and lower salinity, particularly during periods of heavy rainfall, which enhance the survival and growth of COTs larvae, due to the increased availability of planktonic food, and leads to subsequent proliferation of adult populations (Birkeland and Lucas, 1990; Ayukai et al., 1997). This outbreak may have been influenced by the fact that the DMRS is in the pathway of northward flowing currents coming from the direction of Dar es Salaam city centre and Msimbazi Creek, which are likely to carry pollutants, particularly during the rainy season (Hamed, 2005). Thus, it is possible that the outbreak was partially a result of the breakage of the sewage pipe at Ocean Road, near the city centre, in 2003, which is discussed in detail below under the section on pollution.

The combination of the above-mentioned pressures on coral reefs, acting cumulatively over the past few decades, has caused substantial state changes in reef ecosystems. Degradation observed in surveys is usually the result of a combination of several pressures. Damage due to dynamite fishing was noticed as far back as the study of
Hamilton (1975). Bryceson (1978) stated that dynamite damage on the reefs of Kunduchi may be largely responsible for poor condition of the reefs and diminished fish catches. Pearson (1988) qualitatively observed that there had been serious coral reef degradation due to dynamite fishing and anchoring on most of the fringing and patch reefs in Dar es Salaam. Coral reef monitoring at a few selected sites at Mbudya and Bongoyo reefs, conducted during 1999 by Mohammed et al. (2000), indicated that there was $14 \%$ and $14.7 \%$ dead coral, respectively. However, Wagner et al. (2001), carrying out a rapid assessment technique around the entire circumference of Mbudya Island in 1999, reported that there was on average $40-60 \%$ cover of dead coral largely as a result of the coral bleaching event of 1998 combined, on the seaward side, with strong wave action and sediment abrasion. Substantial damage from dynamite fishing was also observed. At Pangavini (Mrema, 2001), other than two patches (northeast and southwest sides) with good coral cover (up to $80 \%$ ), the rest of the reef was primarily rubble $(77.5 \%)$, probably due to a combination of dragging seine nets, dynamite fishing, coral bleaching and wave action. Likewise, Fungu Mkadya was dominated by rubble (60\%) (Bipa, 2000). At Fungu Yasin, there were patches of hard coral (32\% cover) on the northwest side, but a large area on the southwest side was almost $100 \%$ rubble, which may be attributed to a combination of destructive fishing and coral bleaching (Peter, 2002).

Though fewer studies have been conducted on the reefs south of the harbour, it appears that the situation is very similar. At Kendwa Island, though there was good coral cover $(51.2 \%)$ on the deeper reef slope on the seaward side, where destructive fishing practices cannot be carried out; on the shallow reef area on the sheltered northwest side where destructive practices still continue, particularly seine net dragging, coral cover was only $2.3 \%$ and rubble was $66.1 \%$ (Mchome, 2002). Similarly on the shallow reef area on south side, which is also prone to destructive fishing practices, hard coral cover ranged from 3.2-15.4\%, while rubble ranged from 10.9-25.4\% (Ibengwe, 2003). The rubble around this island was probably due to a combination of destructive fishing practices and coral bleaching. 


\section{Mangrove Forests}

The causal chain analysis by Francis et al. (2001) revealed that the major pressures causing the loss and modification of mangrove ecosystems in Tanzania were the over-harvesting of mangroves (thought to account for $46 \%$ of the degradation) for firewood, charcoal-making, building poles and boat-making; as well as clear-cutting (30\%) for aquaculture, agriculture, solar salt works, road construction, urbanization and hotel construction. Wagner et al. (1999) showed that this analysis also applies fairly well to Dar es Salaam, where, at Kunduchi and Mbweni, the main purpose for which mangroves are cut is the production of firewood (mentioned by $25 \%$ of the interviewees), followed by clearing for building sites (19\%), construction poles $(16 \%)$, and charcoal-making (12\%). Also, sizeable areas of mangrove forests in this area have been cut for solar salt pans, hotel sites (though these were eventually abandoned) and other types of construction.

Another pressure on mangroves, though fortunately not widespread, was reported by Akwilapo (2001) who noticed fishermen dragging seine nets under the canopies of large Sonneratia trees in the lower zone of Mtoni Kijichi mangrove forest at the upper end of Dar es Salaam harbor (Fig. 1). This resulted in no saplings or seedlings being observed in that zone. Moreover, the few mature trees remaining were being cut at an alarming rate. Over a period of just a few months, basal area of mangroves dropped from 23 to $7 \mathrm{~cm} / \mathrm{m}^{2}$, while the basal area of stumps rose correspondingly.

An additional pressure on the Mbweni mangrove forest is sedimentation of the water inlet from the ocean, which limits tidal flow and which may be related to agricultural practices and deforestation in the area. This results in a peculiar characteristic of this forest in that it is not inundated by semi-diurnal tides as are most forests in Tanzania; rather, it is inundated only every two weeks during high spring tides or sometimes only once per month (Wagner et al., 2001).

Due to these pressures, there have been drastic state changes in most of the mangrove forests of Dar es Salaam over the past decades. Machumu (1996) already noted that there had been heavy cutting pressure at Kunduchi at the time of his study.
However, the density of mangroves continued to drop from 0.26 mature trees, 0.68 saplings and 2.76 seedlings per $\mathrm{m}^{2}$, according to his study, to 0.13 mature trees, 0.27 saplings and 2.62 seedlings per $\mathrm{m}^{2}$, according to data recorded during 2003 (Wagner, 2005). At Mbweni mangrove forest, though considerable cutting of mangroves had taken place before 1989, according to aerial photographs taken in that year, the average stand height was still about 10 m (Semesi, 1991). However, by 2002, very few mangrove trees were found to reach that height (Wagner et al., 2001). Moreover, Akwilapo (2001) found very low densities of mangroves in three sites in this forest, recording $0.005-0.226$ mature trees, $0.014-0.234$ saplings and $0.156-0.311$ seedlings per $\mathrm{m}^{2}$. She also recorded $0.32 \mathrm{stumps} / \mathrm{m}^{2}$ at one of the sites. At Mbweni, selective cutting pressure over the decades, particularly of the popular Rhizophora mucronata, has resulted in a shift in species composition, with seedlings and saplings of the fast-regenerating species, Ceriops tagal, now dominating. Moreover, Sonneratia alba has all but disappeared from this forest (Wagner et al., 2001). Kunduchi and Mbweni mangrove forests, in fact, have become characterized by fragmentation. At Dege mangrove forest near Ras Kimbiji (Fig. 1), which is located in a sparsely populated area of Dar es Salaam $60 \mathrm{~km}$ south of city centre, the situation is only slightly better. Sallema (2002) recorded 0.35 -0.49 mature trees, $0.05-0.58$ saplings, $0.04-2.65$ seedlings and $0.07-0.38$ stumps per $\mathrm{m}^{2}$.

In order to get an impression of the relative state of Dar es Salaam mangroves forests, a comparison of data obtained using the same methodology reveals that basal area at Mbweni and Kunduchi was 85 and $64 \mathrm{~cm}^{2} / 25-\mathrm{m}^{2}$ plot, respectively; while at nearly pristine forests in Tanzania much high basal area was recorded, such as $1,261 \mathrm{~cm}^{2} / 25-\mathrm{m}^{2}$ plot at Kifuma in the Rufiji Delta (Wagner, 2005) and $1,015 \mathrm{~cm}^{2} / 25-\mathrm{m}^{2}$ plot in the Ruvuma Estuary (Wagner et al., 2004).

\section{Seagrass Beds}

The causal chain analysis by Francis et al. (2001) revealed that the major pressure causing the degradation of seagrass beds in Tanzania has been destructive fishing practices, particularly beach seining and industrial trawling, thought to account 
for about $64 \%$ of the degradation. In Dar es Salaam, however, of these two methods, only beach seining is practiced, which is carried out by artisanal fishermen in the intertidal and shallow subtidal zones. This involves dragging small-mesh sized nets, weighted at the bottom, over the substratum, which scrapes up seagrasses and associated fauna and flora as well as disturbing the habitat. Francis et al. (2001) also showed that a second important pressure on seagrass beds is the movement of boats and people, thought to account for $20 \%$ of the degradation. In Dar es Salaam, large numbers of local residents and tourists are involved in various beach activities such as beach walking, swimming, dragging boats, fishing, selling fish, collecting curio, etc., which cumulatively can have considerable impact on seagrass beds and their biodiversity. A study by Mwaigomole (2001) compared seagrass beds at the Mbweni fish landing site with those in a relatively undisturbed (control) site just a few hundred meters away. Seagrass abundance was found to be significantly lower in the fish landing site $(27 \%$ cover) than in the less disturbed area (63\% cover). At the same time, there were no significant differences between the two study sites in abiotic factors such as percentage pore water and percentage organic matter, indicating that the difference in seagrass abundance was probably due to human activities that take place at the fish landing site, such as the anchoring and dragging of boats as well as excessive movement of people. The results also showed minor negative impact on macrofauna at the fish landing site. In addition, seagrass beds are undoubtedly affected by sedimentation brought about by various factors, which will be discussed below under pollution.

\section{Fisheries}

Heavy fishing pressure or overfishing, which is invariably accompanied by catching juveniles with consequent low fish recruitment, has serious impacts on fisheries and is one of the serious problems in Dar es Salaam (Wagner et al., 1999). It also affects the health not only of keystone coastal ecosystems like coral reefs (Horrill et al., 2000), but also the biodiversity and ecological integrity of the entire coastal pelagic system.
The over-fished condition was indicated by low fish abundance $(200 \mathrm{~kg} / \mathrm{ha})$ in the DMRS, with small-bodied fish contributing $70 \%$ of the total wet weight (McClanahan et al., 1999). Strong evidence of overfishing was provided by the relationship between the number of fishers versus the total catch at Kunduchi and Msasani landing sites between 1971 and 1992. The optimum level of production was 700 metric tons caught by 1,150 fishers. Thereafter, the curve drops, though the number of fishers rises to over 1,400 (Horrill et al., 2000). Further evidence of overfishing is shown by data obtained from the Fisheries Division of the Ministry of Natural Resources and Tourism, from 1985 to 2000 , whereby the number of fishers operating at Kunduchi fish landing site rose from 548 to 4,216 and the number of vessels rose from 384 to 2,620 . During the same period, the catch per fisher dropped drastically from 29.2 to $6.5 \mathrm{~kg} /$ person (Wagner, 2002). This indicates that the amount of fish available in the coastal waters of Dar es Salaam had decreased considerably. This observation is supported by the perception of local fishermen, whereby $49 \%$ of the fishermen interviewed by Wagner et al. (1999) said that fish catches had decreased over the past few years, while another $26 \%$ said catches had decreased greatly.

Benno (1992), investigating the effects of beach seine fishery at the Kunduchi coast, showed that $50 \%$ of the catch comprised herbivorous fish (Scaridae and Siganidae). Of all the catch landed by beach seines, $51.3 \%$ was immature, $37.8 \%$ had developing gonads and only $7.8 \%$ were in spawning state. Thus, almost $90 \%$ of the beach seine catch had no chance to spawn in their life time. Most of the beach seines used had mesh size not exceeding $12 \mathrm{~mm}$.

Overexploitation of fisheries resources other than finfish also has critical impacts on important species. In Dar es Salaam, there has been rampant collection, over several decades, of ornamental corals and shells for sale as curio. Some of the more beautiful shells are in danger of local extinction (Kayombo, 1988). In addition, there have been recent reports of marine turtle and dolphin butchering in the DMRS. Poachers kill these animals and sell the meat to residents of Mbweni and Kunduchi. The two species which are found in the reserves are endangered animals, 
protected under the Convention on International Trade in Endangered Species of Wild Fauna and Flora (CITES) (Board of Trustees for Marine Parks and Reserves Tanzania, 2005).

Sometimes heavy fishing pressure is species specific, i.e., directed towards certain types of fish that are preferred. This can result in an alteration in species composition and an imbalance in trophic structure, which can ultimately have negative impacts on the environment. For example, McClanahan et al. (1999) found that there had been a loss of a keystone predator species, the triggerfish, in the Dar es Salaam reefs and elsewhere in East Africa. The triggerfish (Balistidae), especially Balistaphus undulatus, a natural predator of sea urchins, normally controls urchin populations. Its depletion had resulted in sea urchin proliferation in Dar es Salaam, with biomass (based on wet weights) of up to $6,000 \mathrm{~kg} / \mathrm{h}$ a recorded (Horrill et al., 2000).

Overfishing can have drastic effects on the health of coastal ecosystems, such as coral reefs. Following through on the example given above, the proliferation of sea urchins due to overfishing the triggerfish has lead to bioerosion of reefs. As sea urchins move over the reef surface to graze on algae, their spines scrape over coral colonies causing damage or death of the corals. Data recorded in the DMRS in 1997 showed a negative correlation between sea urchin wet weights and hard coral cover (McClanahan et al., 1999). Overfishing undoubtedly has negative impacts on other ecosystems, such as mangroves and seagrass beds, though no information could be found to verify this in the Dar es Salaam situation.

Thus, the environmental state changes caused by overfishing and catching juveniles are not only the depletion of fish stocks, but also alteration of species composition, loss of biodiversity, disruption of food webs and trophic structure, and disturbance of the natural balance of marine ecosystems (Wagner, 1998, 1999).

\section{Water Quality}

In Dar es Salaam, there are several types or sources of pollution that deteriorate water quality including sewage, heavy metal pollution, hydrocarbon pollution, other types of industrial pollution, solid wastes, agrochemical pollution and sedimentation (Mashauri \& Mayo, 1990; Machiwa, 1992). Polluting emissions, as pressures, cause environmental state changes concurrently in many types of coastal ecosystems and their biodiversity.

The Dar es Salaam city sewage system dumps raw sewage into the ocean through a pipe at Ocean Road beach near the city centre. Though the pipe is $1 \mathrm{~km}$ long, it broke in 2003 and, since then, has been discharging sewage onto the beach just $24 \mathrm{~m}$ from the high spring tide mark, which is several hundred meters from the low tide mark. Therefore, throughout most of each tidal cycle, the sewage falls on the exposed substratum. Investigations showed that nutrient levels (nitrate, ammonium, and phosphate), turbidity, biological oxygen demand, sediment organic matter and macroalgal biomass were significantly higher near this discharge point at Ocean Road than at an unpolluted site at Mbweni, about $30 \mathrm{~km}$ north of Ocean Road beach. On the other hand, seagrass abundance and diversity as well as macrofauna diversity were lower at Ocean Road than Mbweni (Chimgege, 2005; Frederk, 2005). Construction of a new sewage pipe is underway.

Even three years before the sewage pipe broke, Munissi (2000) demonstrated significant impacts of the raw sewage being discharged by the pipe $1 \mathrm{~km}$ from shore, using green algae as indicator species. Ulva spp. and Enteromorpha spp. showed between $50 \%$ and $71 \%$ cover at sites along the beach within $1 \mathrm{~km}$ of the pipe, while there was less than $3 \%$ cover at sites ranging from $2.5-6.0 \mathrm{~km}$ south of the pipe, which is the opposite direction from prevailing ocean currents. At the same time, with increasing distance from the pipe, there was significant decrease in biological oxygen demand and increase in dissolved oxygen.

Heavy metal pollution is another important issue. In Dar es Salaam Harbour, mercury, lead, chromium, copper and zinc in the sediments exceeded the Florida no effect levels at most sampling stations prior to dredging in 1999 (Machiwa, 2000). Moreover, levels of lead, zinc and copper (all found to be of anthropogenic origin) in mangrove sediments and crabs were higher in concentration in two mangrove forests near Dar es Salaam city centre (Mtoni and Msimbazi) than in a forest on the edge of the city (Mbweni) (Mremi 
\& Machiwa, 2003). Heavy metal enrichment was higher in crabs than in sediment, particularly copper which was six times more concentrated in the former than the latter.

There are a variety of industries in Dar es Salaam that emit non-biodegradable substances into Dar es Salaam Harbour, Msimbazi Creek and other streams, which eventually make their way to the ocean. These substances include plastics, hydrocarbons, dyes, food preservatives, paints and heavy metals. Heavy metals are concentrated in living tissues as they move up the food chain (Mashauri \& Mayo, 1990).

Another issue in the Dar es Salaam area is sedimentation, which has a number of sources including construction along the streams and coastline, deforestation and poor agricultural practices in the area, overgrazing and movement of livestock in peri-urban settlements and the large, high-speed boats operating between Zanzibar and Dar es Salaam, which pass through the shallow waters of the lagoon between the islands and coast, re-suspending sediments with their powerful engines. The sediments from these various sources have negative impacts on coral reefs, seagrass beds, algal beds and other aspects of the marine environment.

The peri-urban Mtoni mangrove ecosystem, which is situated on both sides of two creeks (Mzinga and Kizinga) that flow into the upper end of Dar es Salaam Harbour, is heavily impacted by anthropogenic activities in and around the forest. Besides domestic pollution, there is influx of agrochemicals and industrial pollutants. Also, cars and trucks are washed along the edges of the streams, causing hydrocarbon and other types of pollution. Studies using stable isotopes of organic carbon and nitrogen in sediments showed that enrichment with ${ }^{15} \mathrm{~N}$ was higher near densely populated areas, due to the emission of domestic sewage, than in other areas. Moreover, there was higher biomass of microalgae and elevated inorganic nutrient levels near sites with high human population. Heavy metal pollution was generally highest along Kizinga stream, where several industries are located. Lead, zinc and mercury exceeded Florida "no effect" levels at one or more sites, indicating significant pollution in the area (Mgaya et al., 2004).

\section{Coastal Erosion/Accretion}

Processes of erosion, sediment transport and accretion are common along the Kunduchi and Mbweni coasts. While shoreline dynamics are largely natural processes, the rate, location and direction of erosion appears to be altered by various human activities that include mangrove cutting, the destruction of coral reefs (which act as natural barriers to wave action) by dynamite fishing, beach seining (which destroys seagrass beds that normally help to stabilize the substratum), construction on the coast, beach activities and sand mining in streams that lead into the ocean (Makota \& Sallema, 2003).

By examining aerial photographs, Mushala (1978) found that, over a 20-year period, there had been shoreline recession of more than 50 metres in front of both Silversands and Kunduchi Beach hotels. According to Kairu and Nyandwi (2000), hotel development and stream bed mining contributed to the loss of 6 ha of beach in a few years at Kunduchi. A study of the KunduchiManyema Creek (Makota \& Sallema, 2003) showed that, between 1981 and 2002, there was erosion of about 6.4 acres on the northern side of the creek. On the southern side, both accretion and erosion occurred. Further south of the creek, erosion was measured at several points along the beach, showing losses of up to $52 \mathrm{~m}$. Coastal erosion led to loss of 1.05 acres of mangroves at Kunduchi-Manyema Creek, and it has destroyed or damaged public and private property along the shore, such as Africana Hotel (Makota \& Sallema, 2003) and houses in the fishing village at Kunduchi (Wagner et al., 1999).

\section{IMPACTS ON HUMAN WELL-BEING}

There is a reciprocal cause-and-effect relationship between poverty and environmental degradation or environmental state change. That is, poverty engenders destructive or inappropriate resource use patterns, which lead to environmental degradation and, in turn, environmental degradation generates further poverty (Moffat et al., 1998). This is particularly true where people have a strong dependence on marine and coastal resources, such as the fishing communities of Dar es Salaam (Wagner et al., 1999). It is a vicious cycle that is difficult to 
break. Referring to the UNEP Human-Environment Interaction Analytical Approach (UNEP, 2006) (Fig. 2), unless there are strong, appropriate responses, the impacts that environmental state changes have on human well-being will feed forward in the cycle and increase the tenacity of drivers such as poverty and poor education. For example, the destruction of coral reefs (environmental state change) can lead to reduction in the availability of fish as a protein food supply (reduced human well-being), which can in turn necessitate fishermen spending money to buy food, leading to their increased poverty (driver). However, the relationship between poverty and environmental degradation is complex and often external factors, such as poor management and lack of community involvement exacerbate both (Ruitenbeek et al., 2005).

According to Moffat et al. (1998), about 50\% of the estimated 100,000 full-time fishermen and several hundred thousand part-time fishermen in East Africa risk losing their livelihood unless the current trend is arrested. Wagner et al. (1999) reported that, according to villagers in the coastal communities, environmental degradation, particularly of the marine ecosystems, is one of the main reasons for their poor economic status, since it has seriously affected fisheries, one of their main sources of livelihood. The drop in catch per fisher, as mentioned above, from 29.2 to $6.5 \mathrm{~kg} /$ person during a span of 15 years (Wagner, 2002), is bound to have had serious repercussions on human wellbeing. Many former fishermen in Mbweni and Kunduchi said that, due to the shortage of fish, they had had to look for other sources of livelihood (Wagner et al., 1999).

The causal chain from polluting emissions, as pressures, to state changes in water quality leads to a range of impacts on human well-being. For example, eutrophication of coastal waters causes changes in fisheries production, leading to poverty and a decrease in protein consumption by coastal dwellers, with implications for human health. Another impact on human health is caused by heavy metal pollution, which becomes progressively concentrated in living tissues at each higher level of the food chain. Thus, when Dar es Salaam residents consume fish and other marine fauna, their health is at risk (Mashauri \& Mayo, 1990).

\section{RESPONSES}

Responses can also generally be considered as management interventions. They may be directed towards all or any of the following - addressing the root causes (drivers), mitigating the pressures, protecting/restoring the state of the environment or dealing with the impacts on human society (Fig. 2). Responses address issues of vulnerability both of people and of the environment. This section is divided into two parts - a brief account of management before the early 1990s, followed by a more detailed account of the subsequent era of integrated coastal management.

\section{Management Prior to the Early 1990s}

The Fisheries Act of 1970 provided for fisheries management, stipulated various regulations and outlawed certain destructive practices such as dynamite fishing. Then in 1975, eight marine reserves, including the Dar es Salaam Marine Reserve System (DMRS), were given legal recognition and were placed under administration of the Fisheries Division. These reserves were supposed to be fully protected, with no extractive use. However, due to lack of capacity to actively manage the reserves, they became merely "paper" reserves (Bryceson, 1981). The Fisheries Act was also generally not enforced and destructive fishing practices continued with increasing intensity for almost three more decades, in Dar es Salaam and elsewhere in the country.

The early approach to management had five serious problems that made it ineffective. Firstly, policies and management strategies remained on paper, with little or no capacity or effort to implement them. Secondly, decision-making was uniformed. Officials made decisions and plans sitting in government offices, with no monitoring or timely field data available to form the basis for sound management. Thirdly, the approach was nonparticipatory and top down. Communities and local authorities were not consulted and felt alienated from the process. Fourthly, the aim in creating reserves was complete protection of the resources (though this was not achieved), rather than sustainable use; thus, further alienating the coastal communities, which consequently gave no support 
for conservation efforts. Fifthly, the approach was sectoral, rather than integrated. There was serious overlap of duties, often several departments being responsible for the same resource.

Consequently, these early efforts were ineffective and basically resulted in mismanagement or no management at all. Negative environmental state changes continued to accelerate as a result of drastically increasing human populations, combined with poverty and inadequate environmental awareness, which put greater and greater pressures on the marine environment and its resources. The Dar es Salaam seascape was truly an environmental 'hotspot' of degradation.

\section{Era of Integrated Coastal Management (ICM) (Early 1990s to the Present)}

In 1993, a resolution was passed on establishing ICM in East Africa by participants at the "Workshop and Policy Conference on Integrated Coastal Zone Management in Eastern Africa including Island States" held in Arusha (Lindén, 1993) which has now become the acceptable approach in Tanzania. This approach considers the coast primarily as a multiple-use zone, wherein all stakeholders, who are either using or managing the area, must be involved in a participatory and continuing process of consultation, planning, implementation, evaluation and re-planning. The key is co-management on an on-going basis. ICM integrates the need for environmental conservation on the one hand and sustainable resource use and development on the other (UNEP, 1989). This approach minimizes damage and maximizes long-term economic and social benefits. ICM also mitigates resource use conflicts (Talbot \& Wilkinson, 2001) by bringing different resource users together to build an attitude of cooperation, to create mutual trust and to make decisions jointly.

\section{National level interventions}

There have been a number of national level interventions that have had definite implications for improved management of the Dar es Salaam seascape. The Ministry of Natural Resources and Tourism instituted the Marine Parks and Reserves Act No. 29 of 1994, which formulated a management framework that emphasized community involvement in conservation and placed all marine protected areas in Tanzania, including the DMRS, under the Marine Parks and Reserves Unit.

In 1997, the National Environment Management Council (NEMC) established the Tanzania Coastal Management Partnership (TCMP) in collaboration with the University of Rhode Island and the United States Agency for International Development (USAID). TCMP has been making efforts to influence government policy and to provide accurate, up-to-date information and guidance to stakeholders and policy makers. TCMP facilitated the production of Tanzania Mariculture Guidelines Source Book (Mgaya et al., 2001) and Guidelines for Coastal Tourism Development in Tanzania (United Republic of Tanzania, 2003a). In addition, TCMP has been offering support to programs, projects and marine parks working at the district and local levels.

Efforts of TCMP towards influencing policy culminated in April 2003 in the launching of the National Integrated Coastal Environment Management Strategy (United Republic of Tanzania, 2003b). The document outlines seven main strategies:

- to support integrated management of coastal resources and activities at the local level, while harmonizing national and local interests;

- to promote integrated, sustainable and environmentally friendly approaches to the development of economic uses of coastal resources;

- to conserve and restore critical habitats and areas of high biodiversity while ensuring that coastal people benefit from the resources they provide;

- to establish an integrated management mechanism for coastal areas having high economic potential and/or having vulnerability to natural hazards;

- to ensure informed decision making by developing and using effective systems of research, monitoring and assessment;

- to ensure stakeholder involvement in ICM planning and implementation; and

- to build both human and institutional capacity for ICM. 
The Strategy also makes provisions for the role that TCMP has been playing to be incorporated into the government by formation of the Integrated Coastal Management Unit (ICMU) within NEMC.

The issue of dynamite fishing was also tackled at the national level. In 1998, the navy and marine police combined forces with local programs throughout the country, which resulted in a significant reduction in dynamite fishing (Horrill \& Makoloweka, 1998). In this crackdown of 1998, 15 people in Dar es Salaam were convicted and fined for dynamite fishing and 29 for using the illegal seine net (Mgaya \& Juma, 2001). The use of dynamite has however re-surfaced, demonstrating the need for continued surveillance and control.

An Environmental Impact Assessment (EIA), an important management tool, is required by The Marine Parks and Reserves Act (1994), The Tanzania Investment Act (1997), the National Environment Policy (1997) and the new Mining Act (1998), before any new development projects can be implemented. Development permits are issued by the NEMC.

The Environmental Management Act of 2004 (United Republic of Tanzania, 2005) provides a legal and institutional framework for sustainable management of the environment and outlines the principles and obligations of environmental management. It gives directives for the following: environmental planning and decision-making, including participation of the public; conservation and protection, including the establishment of protected areas; environmental impact assessment (EIA); pollution prevention and control as well as waste management; environmental information, education and research; environmental restoration; compliance and enforcement; and linkages with international and transboundary agreements. Though the Act is directed towards the environment of Tanzania in general, it is very applicable to marine and coastal issues.

Blueprint 2050 (Ruitenbeek et al., 2005) is a national level initiative, that was produced out of a process of collaboration amongst several bodies of the Government of Tanzania, international organizations, non-governmental organizations and researchers, supported by World Bank and endorsed by the Vice-President's Office. Blueprint 2050 provides the vision and calls for the establishment of a system of eight networks of marine protected areas that will cover $10 \%$ of Tanzania's coastal and marine areas by 2012 and $20 \%$ by 2050 .

Tanzania is also party to regional and international conventions and protocols pertaining to the coastal zone such as the Nairobi Convention and Protocols of 1985, the Convention on Biological Diversity of 1992, the UN Framework Convention on Climate Change of 1992, the UN Law of the Sea Convention of 1958, the Convention on International Trade in Endangered Species of Wild Fauna and Flora (CITES) of 1973, the International Convention for the Prevention of Pollution from Ships (MARPOL) of 1978, the Ramsar Convention on Wetlands of 1971 and many others (Mgaya \& Juma, 2001).

\section{Marine Action Conservation Tanzania (MACT)}

The first activity undertaken by MACT, a nongovernmental organization (NGO) registered in 1997, was to patrol for dynamite fishing in Dar es Salaam. Later, MACT worked with local communities in Kunduchi and Mbweni in coral reef and mangrove restoration as well as ecotourism.

In a project undertaken in 1998 by MACT in collaboration with AGENDA and the University of Dar es Salaam, the women of Mbweni Village were trained to transplant mangrove seedlings and propagules in clear cut areas of Mbweni mangrove forest. More than 3,000 seedlings/propagules (primarily Rhizophora mucronata) were planted. This mangrove replanting activity resulted in the spontaneous formation of a new CommunityBased Organization (CBO) known as Mbweni Environment and Women's Group (Wagner et al., 1999). An assessment done at two sites after eight months showed that $50 \%$ of the transplants had survived. Likely causes of the low survival rate are the low frequency of tidal inundation at Mbweni due to sedimentation of the water inlet (explained above under pressures on mangroves) and the fact that some open areas had been cut more than two years previously, such that soil properties are likely to have changed (Wagner et al., 2001). Nevertheless, probably more than 1,000 seedlings survived and, after several years of growth, have now become saplings and young trees. 
The same project of 1998 also involved local fishermen from Kunduchi in restoring coral reefs in the DMRS. Initially, about 500 coral fragments were transplanted in five dynamited sites on Mbudya Island reef (Wagner et al., 1999). Amongst the 342 coral fragments that could be relocated, survival was very good for Galaxea sp. (100\%), Montipora (76.6\%) and Acropora (74.6\%), but not so good for Porites sp. (55.7\%) (Wagner et al., 2001).

In 1999, MACT also began working with the local communities in organizing ecotours, combined with restoration, which was an ongoing, alternative income-generating project for Kunduchi and Mbweni communities for several years (Wagner et al., 2001). Transplanting corals or replanting mangroves as part of each ecotour provides economic benefits to the community and also motivates them to restore their ecosystems. The conducting of many ecotours over a period of several years has had substantial positive impacts on the targeted ecosystems. There has been visible acceleration of reef recovery at Mbudya Island and many of the previously open areas of Mbweni mangrove forest are now filled with young mangrove trees as a result of the efforts of Mbweni Environment and Women's Group (Wagner et al., 2001; Wagner, 2002).

Although MACT is not active at present, many of its functions have been taken over by Kinondoni Integrated Coastal Area Management Program described below.

\section{Kinondoni Integrated Coastal Area Management Program (KICAMP)}

KICAMP was launched in Dar es Salaam in May 2001, focusing on two pilot coastal communities, Kunduchi and Mbweni. The overall objective of KICAMP is to achieve sustainable management of natural resources such that they will be conserved for future generations while, at the same time, they are being used to improve the living standards of the current generation. Phase I involved four major components: surveys, research and monitoring; education, communication and information; land and water use planning; and community development (Kinondoni Integrated Coastal Area Management Program, 2001). During Phase II of KICAMP, launched in 2005, the same four components continue, but emphasis is on capacity building within the Municipal government and the coastal communities so that they can sustainably manage their resources (Kinondoni Municipal Council, 2003).

In Phase II, the programme has been expanded to include three additional coastal communities, namely, Boko, Bunju and Ununio. It has been compiling an integrated set of resource management plans for the coastal and marine resources in the area; strengthening awareness of natural resources and environmental issues at all levels, with vertical exchange of views and information; implementing sustainable job-creation activities to improve living standards; and finally, obtaining greater understanding of the status of the resources and appropriate thresholds to be applied for their sustainable utilization. KICAMP has signed memoranda of understanding with two components of the University of Dar es Salaam, i.e., the Institute of Marine Science, for ecological mapping, and the Faculty of Aquatic Sciences and Technology, for monitoring and assessment (Kinondoni Municipal Council, 2003). The latter has involved the local communities in participatory monitoring of coral reefs, mangroves, seagrass beds, fisheries and terrestrial flora and fauna.

Mbweni Environment and Women's Group, whose formation was facilitated by MACT, continues to operate under the guidance of KICAMP, with on-going engagement in mangrove replanting and ecotourism. The effectiveness of community-based restoration efforts in Mbweni mangrove forest, from the time of MACT to the era of KICAMP, was evaluated by Nderumaki (2004). She showed that these restoration projects had significant positive impact on mangrove abundance and diversity. Moreover, there was a significant positive correlation between transplanted mangrove growth and soil organic matter, indicating that in mangrove areas that have been deforested for a long period, replenishment of the biota can lead to the improvement of soil properties within only a few years.

While KICAMP is making great effort to plan and implement, through a participatory process with the five main communities that utilize the marine resources in Kinondoni District, they have minimal influence over people coming from other communities to utilize marine resources in 
Kinondoni. Moreover, their hands are virtually tied with respect to the discharge of pollution into the ocean, most of which comes from the other two municipalities of Dar es Salaam, Ilala and Temeke.

\section{Dar es Salaam Marine Reserves System (DMRS)}

As mentioned above, the DMRS includes four reserves, Fungu Yasini, Mbudya, Pangavini and Bongoyo, whose outer limits are defined by a 10 $\mathrm{m}$ depth contour. Basically, no management took place for over two decades after its establishment. In 1994, DMRS was placed under the Marine Parks and Reserves Unit (MPRU) and, since then, a collaborative management approach has been taken (Horrill et al., 2000). MPRU has been enforcing regulations and conducting surveillance for destructive fishing practices in the DMRS through cooperation with the marine police; has engaged local youth as honorary rangers, giving them training in customer care and hospitality; has conducted awareness raising activities amongst fishermen and has constructed mooring buoys near some reefs to help prevent anchor and boat grounding damage (Wagner, 2004a; Board of Trustees for Marine Parks and Reserves Tanzania, 2005).

Key stakeholders of the DMRS include fishers, research and academic institutions, tour operators, hoteliers, local government and, visitors to the reserves. Local fishing communities in the vicinity include Mbweni, Ununio, Kunduchi, Msasani, and Banda Beach, all of which have fish landing sites. About 4200 fishermen operate from communities close to the DMRS. The majority of the non-resident fishermen in Kunduchi are seasonal fishermen who travel from Mafia, Pemba, Tanga and Mtwara. Various hotels and dive centres, as well as Dar es Salaam Yacht Club, carry out recreational activities in the DMRS (Roxburgh et al., 2002).

In 2005, the Board of Trustees for Marine Parks and Reserves Tanzania developed the Dar es Salaam Marine Reserves General Management Plan as a tool to effect the protection and conservation of biodiversity in the reserves and to ensure sustainable resource utilization. The objectives of the plan are:
- to protect, conserve and restore species, genetic and ecosystem biodiversity in the DMRS as well as all living and non-living resources;

- to promote sustainability of non-extractive resource use; to ensure stakeholder involvement in all phases of planning and management;

- to promote community education and information dissemination; to facilitate research and participatory monitoring within the DMRS; and

- to improve the regulatory and institutional framework for management in the DMRS (Board of Trustees for Marine Parks and Reserves Tanzania, 2005).

All extractive uses in the reserves are prohibited including fishing, collection of fish bait, tree cutting, collection of marine and terrestrial organisms as well as coral mining. Certain types of recreational activities, such as SCUBA diving, require a permit. The General Management Plan also provides a guide for zoning each of the island reserves into areas of particular conservation interest or uses. In addition, a buffer zone has been designated for a distance of $800 \mathrm{~m}$ peripheral to each island reserve, as an area that serves as a cushion against activities taking place outside the area. However, as yet, marine reserves have no direct jurisdiction over activities in the buffer zone.

In response to reports that COTs were found in great densities in the DMRS, MPRU implemented a clean up. With the assistance of fishermen in the area, they collected COTs by the sack full and buried them on the beach. In total, 995 COTs were removed, 194, 401, 12 and 348 from Bongoyo, Mbudya, Pangavini and Fungu Yasini, respectively (Julius, 2005).

\section{Other Responses}

Non-governmental organizations and the Private Sector have also responded to environmental problems. For example, in an effort to mitigate the effects of coastal erosion, groynes were placed on the foreshore in front of Bahari Beach, Silversands and Kunduchi Beach Hotels (Kairu \& Nyandwi, 2000). However, it appears that further research is required to determine the most effective ways of protecting the coast from erosion, particularly 
low-cost methods which could be used by the local communities (Wagner, 2002).

\section{OUTSTANDING AND EMERGING ISSUES}

Though the multiple responses made at both the national and local levels appear to be having some positive impacts, many of the problems remain largely unsolved. The principal outstanding issues or pressures include increasing demands for marine and coastal resources due to rapid population rise; persistence of destructive fishing practices; unsustainable resource utilization, particularly overfishing and overharvesting of mangroves, excessive collection of molluscs and sea cucumbers; and pollution of various types. Fine-mesh seine nets (i.e., nets with meshes of $1 \mathrm{~cm}$ ), which are illegal, continue to be manufactured by local industries and are readily available in the shops (Kinondoni Municipal Council, 2003; Wagner, 2004a; Board of Trustees for Marine Parks and Reserves Tanzania, 2005).

Despite efforts by KICAMP, mangrove stand basal area dropped at Mbweni from $89.0 \mathrm{~cm}^{2} / 25$ $\mathrm{m}^{2}$ plot in 2002 to 67.4 in 2003, while at Kunduchi it dropped from 63.9 to 61.9 during the same time period (Wagner, 2004b; Wagner, 2005).

While tourism has been an on-going activity in Dar es Salaam for many years, tourist numbers are steadily increasing and local residents are now also taking more interest in recreational activities on the beaches, islands and coral reefs. Large numbers of visitors to DMRS congregate on small sandy beaches and tourist boats are becoming numerous (Board of Trustees for Marine Parks and Reserves Tanzania, 2005). No evaluation has been carried out on the tourist carrying capacity of DMRS and other recreational areas in Dar es Salaam.

Clear cutting of mangroves is still going on despite efforts by various government departments and non-governmental organizations. During monitoring training conducted in 2005 through collaboration between KICAMP and the Faculty of Aquatic Sciences and Technology of the University of Dar es Salaam, it was observed that a large area (about $300 \mathrm{~m} \times 250 \mathrm{~m}$ ) of mangroves at Ununio had recently been clear cut.

\section{CONCLUSIONS}

Analysis of the Dar es Salaam seascape as an environmental 'hotspot' of degradation, using the DPSIR Framework, indicates that the main drivers of change have been rapid population growth combined with poverty and inadequate education. These have led to a variety of pressures, which have often been specific to certain coastal and marine ecosystems. In turn, these pressures have resulted in substantial negative environmental state changes, in particular, loss and modification of habitats, loss of biodiversity, reduction in fisheries resources and deterioration of water quality. Consequently, the reduction in natural resources has contributed to further poverty, particularly for the residents of the Dar es Salaam fishing communities.

The early approach to management, from about 1970 until the early 1990s, had several serious problems and was thus ineffective, basically resulting in mismanagement or no management at all. Decisions and plans were made with little relevant information available. Moreover, planning was non-participatory, such that the communities felt alienated from the process. The approach was sectoral, rather than integrated and was aimed towards complete protection of resources, rather than their sustainable use. For the most part, policies and management strategies remained on paper, with little or no capacity or effort to implement them.

Commencing in the early 1990s, the ICM approach was adopted in Tanzania. Thereafter, many innovative interventions have been initiated at the national level, such as the establishment of TCMP to provide up-to-date information, support and guidance to the government, stakeholders and ICM programmes throughout the country; the launching of the National Integrated Coastal Environment Management Strategy (United Republic of Tanzania, 2003b); the requirement that an Environmental Impact Assessment (EIA) be conducted before any new development projects can be implemented; and the establishment of the Environmental Management Act of 2004 (United Republic of Tanzania, 2005), which provides a legal and institutional framework for sustainable management of the environment. 
Three initiatives, MACT, KICAMP and DMRS, have done much to implement the ICM approach along the northern coast of the Dar es Salaam seascape. They have largely succeeded in enhancing environmental awareness amongst the targeted fishing communities and to involve them in co-management. They have also made efforts towards poverty alleviation.

However, these three initiatives have minimal influence over people coming from other fishing communities that they have not targeted, i.e., those along the central and southern coast of Dar es Salaam. Moreover, their hands are virtually tied with respect to the discharge of pollution into the ocean, most of which comes from industries and domestic areas of Dar es Salaam located away from the coast.

Though the many national and local level responses seem to be bringing about some improvements, due to the highly complex social issues associated with the large metropolis of Dar es Salaam and the intricacies of the seascape interactions, there are still many critical, outstanding and emerging issues that remain unsolved. The main outstanding issues or pressures include rising demands for coastal and marine resources due to the high rate of human population increase; unsustainable and destructive utilization of resources; and pollution

\section{RECOMMENDATIONS FOR MANAGEMENT}

One of the major recommendations that can be made from the above analysis is that there should be the formation of a single, all-encompassing ICM program covering the entire Dar es Salaam seascape. This type of approach is essential since it is impossible to have successful results in Dar es Salaam through the current 'piecemeal' management, whereby a few programmes/ institutions (e.g. MACT, KICAMP and DMRS) have been focussing on very limited geographical areas. The drivers and pressures that bring about state changes in the environment are very complex and interactive. For example, there is free movement of fishermen from the southern part of Dar es Salaam to the north part and vice versa, thus attempting to manage fishermen from only some areas is inadequate. Moreover, state changes in one part of Dar es Salaam affect other parts of the seascape. Various types of pollution from residences and industries all over the city are discharged to the ocean, through the Dar es Salaam estuary, various streams and run off. Due to the prevailing northward movement of currents, pollution is carried through the seascape affecting marine life over a much broader area.

This idea of managing the entire Dar es Salaam seascape as a whole is supported by the views of Dudley et al. (1999 in Francis et al., 2002) that protected areas in eastern Africa must expand in size, in concept and in stakeholder participation, connecting to the wider seascape, thus moving from 'islands' to 'systems'. A key aspect of successful ICM in a complex situation such as occurs in the Dar es Salaam seascape would be appropriate zoning (including buffer zones) into areas of multiple use, areas of specialized use and core protected areas. Such zoning would require research and assessment as well as broad stakeholder involvement.

The root causes or drivers of change are primarily socio-economic in nature and therefore major efforts need to be made to improve human well-being. The vicious cycle of poverty, ignorance and environmental degradation will only be broken through responses or interventions that put the wellbeing of local people at the forefront (Moffat et al., 1998). For coastal communities who rely heavily on natural resources, this requires two strategies. One is to reverse the process of environmental degradation through protection and restoration so as to renew the availability of coastal and marine resources that provide a livelihood for these communities. The second is to create alternative sources of income or diversify the livelihoods in order to relieve some of the pressure on the natural resources, particularly in the marine environment.

Due to the escalating population of Dar es Salaam, more and more people will necessarily have to be guided to the second strategy since the limit of sustainable utilization of the coastal and marine resources in Dar es Salaam, or the carrying capacity of the environment, has long been surpassed with respect to most resources. The first strategy is actually directed towards improving environmental state. Since the environment in the Dar es Salaam seascape is already highly degraded, 
the negative environmental state changes will have to be reversed. There must be increased efforts in protection of habitats, along with their flora and fauna, which requires eliminating destructive fishing practices and fostering sustainable utilization of resources. This entails enhancing environmental awareness, instilling a feeling of ownership of the environment amongst fishing community members, participatory planning, empowering fishermen to obtain environmentally friendly gear and enforcing laws and regulations adequately.

However, in habitats where severe degradation has occurred, active ecosystem restoration is required in order to facilitate recovery within a reasonable length of time and to return the original species diversity. Community-based restoration is recommended, as has already been undertaken successfully in coral reefs and mangrove forests in Kunduchi and Mbweni (described above under 'Responses'). Intensification and expansion of these activities could have profound positive impact on the habitats.

Research, assessments and regular monitoring are necessary in order to plan effective conservation and/or restoration actions. Proper management cannot take place unless there is sound scientific information about the status of the environment and its resources (Francis et al., 2002). Long-term monitoring is important since it can detect both negative trends, due to on-going pressures on the resources, as well as positive trends, due to effective interventions. Again, the participatory approach is very effective since it greatly increases the manpower for monitoring and enhances awareness (Wagner, 2005).

The second strategy for dealing with poverty in communities that depend heavily on natural resources, i.e., diversification of livelihoods, can have three approaches, operating concurrently. One approach is to continue to derive income from the marine environment, but to switch from extractive to non-extractive uses of the environment, e.g., by involving the community in ecotourism. The second approach is extractive, but involves resources for which assessments have shown further expansion is possible (e.g. sardine fishery) or those that have been deliberately introduced and cultured, i.e., mariculture. The third approach is to empower people to take up new livelihoods that have nothing to do with the use of natural resources. This approach requires improving standards of education, offering specialized courses or training and/or providing capital for people to establish small businesses.

Ecotourism aims at benefiting the environment and the residents of the area at the same time (Dimanche \& Smith, 1996). When the local resource users are involved in ecotourism, it improves their economic status and motivates them to protect and conserve the ecosystems where the tourists are taken. In fact, ecotourism can be combined with restoration, as has been done in Kunduchi and Mbweni.

Mariculture is another, yet untapped, but potentially viable opportunity which can be developed in Dar es Salaam. Seaweed farming, oyster culture and fish culture are some of the types of mariculture that could be established. However, further research is required in other to select the most appropriate sites and suitable species for culture.

Though the Dar es Salaam seascape has been largely unmanaged or mismanaged in the past, positive responses over the past decade have begun to bear fruit. Through the pursuit of more strategic and effective interventions, this seascape could be developed into an attractive example of integrated coastal management, encompassing extraction and conservation.

\section{REFERENCES}

Akwilapo, F.D. (2001) The distribution and abundance of mangrove species and associated macrobenthos in ecosystems with varied anthropogenic degradation. M.Sc. thesis, University of Dar es Salaam. 111 pp.

Andersson, J. (1998) The value of coral reefs for the current and potential tourism industry on Unguja Island, Zanzibar. In: Johnstone, R.W., Francis, J. \& Muhando, C.A. (eds.) Coral reefs: Values, threats, and solutions. Proceedings of the national conference on coral reefs, 2-4 December 1997 , Zanzibar, Tanzania. Institute of Marine Sciences (University of Dar es Salaam), Zanzibar, Tanzania. pp. 82-90.

Ayukai, T, Okaji, K. \& Lucas, J.S. (1997). Food limitation in the growth and development of Crown-of-thorns starfish larvae in the Great 
Barrier Reef. Proceedings of the 8th International Coral Reef Symposium 1: 621-626.

Benno, B.L. (1992). Some features of beach seine fishery along the Dar es Salaam coast, Tanzania. M.Sc. thesis, University of Kuopio, Finland. 68 pp.

Bipa, J.D. (2000) Habitat survey and distribution of coral genera, fish and invertebrates on the fringing reef of Pangavini Island. A report submitted in partial fulfilment of the Degree of Bachelor of Science at the University of Dar es Salaam. Department of Zoology and Marine Biology, University of Dar es Salaam. 15 pp.

Birkeland, C. \& Lucas, J.S. (1990). Acanthaster planci: Major Management Problem of Coral Reefs. CRC Press, Boca Raton, Florida. 257 pp.

Board of Trustees for Marine Parks and Reserves Tanzania. (2005) Dar es Salaam Marine Reserves General Management Plan. Board of Trustees for Marine Parks and Reserves Tanzania, Dar es Salaam.73 pp.

Bryceson, I. (1977) An ecological study of the phytoplankton of the coastal waters of Dar es Salaam. Ph.D. thesis, University of Dar es Salaam. $442 \mathrm{pp}$.

Bryceson, I. (1978) Tanzanian coral reefs at risk. New Scientist 80: 115.

Bryceson, I. (1981) A review of some problems of tropical marine conservation with particular reference to the Tanzania coast. Biol. Cons. 20: 163-171.

Chambo, B.J.Y. (1997) Women's economic activities and environmental degradation: The case of Kinondoni District, Dar es Salaam. A dissertation submitted for partial fulfillment of the requirement for the degree of Master of Arts (Demography) of the University of Dar es Salaam. Dar es Salaam, Tanzania. 100 pp.

Chimgege, J.H.H. (2005) Influence of sewage pollution on seagrasses and seaweeds at Ocean Road Beach, Dar es Salaam, Tanzania. A dissertation submitted in partial fulfillment of the requirements for the degree of Master of Science (Environmental Science) of the University of Dar es Salaam, Dar es Salaam. 100 pp.

Dimanche, F. \& Smith, G. (1996) Is ecotourism an appropriate answer to tourism's environmental concerns? Journal of Hospitality and Leisure Marketing 3(4): 67-76.

Francis, J., Nilsson, A. \& Waruinge, D. (2002) Marine protected areas in the eastern African region: How successful are they? Ambio 31(7-8): 503-511.

Francis, J., Wagner, G.M., Mvungi, A., Ngwale, J. \& Sallema, R. (2001) Tanzania National Report, Phase I: Integrated Problem Analysis. GEF-MSP Sub-Saharan Africa Project on "Development and
Protection of the Coastal and Marine Environment in Sub-Saharan Africa. 60 pp.

Frederk, G. (2005) Influence of sewage pollution at Ocean Road Beach on the marine environment. A dissertation submitted in partial fulfillment of the requirements for the degree of Master of Science (Environmental Science) of the University of Dar es Salaam, Dar es Salaam. 113 pp.

Guard, M. \& Masaiganah, M. (1997) Dynamite fishing in southern Tanzania, geographical variation, intensity of use and possible solutions. Mar. Poll. Bull. 34(10): 758-762.

Hamed, S.S. (2005) Assessment of Crown-of-Thorns Starfish populations in the Dar es Salaam Marine Reserves System: A potential threat to coral reefs. A report submitted in partial fulfilment of the Degree of Bachelor of Science at the University of Dar es Salaam. Department of Zoology and Marine Biology, University of Dar es Salaam. 41 pp.

Hamilton, H.G.H. (1975) A description of the coral fauna of the East African Coast. M.Sc. thesis, Vol. 1 (Text), University of Dar es Salaam. 264 pp.

Hamilton, H.G.H. \& Brakel, W.H. (1984) Structure and coral fauna of East African reefs. Bull. of Mar. Sci. 34(2): 248-266.

Hartnoll, R.G. (1975) The ecology of some rocky shores in tropical East Africa. Estuar. Coast. Sci. 4: 1-21.

Horrill, J.C., Kamukuru, A.T., Mgaya, Y.D. \& Risk, M. (2000) Northern Tanzania and Zanzibar. In: McClanahan, T.R., Sheppard, C.R.C., \& Obura, D.O. (eds.) Coral reefs of the Indian Ocean: Their ecology and conservation. Oxford University Press, Oxford, U.K., pp. 167-198.

Horrill, J.C. \& Makoloweka, S. (1998) Silencing the dynamite fisheries along the Tanga Coast, Tanzania. Paper presented at the International Tropical Marine Ecosystem Management Symposium, 23-26 November 1998, Townsville, Australia. 9 pp.

Ibengwe, L. (2003) The status of southern side of Kendwa Island coral reef. A report submitted in partial fulfilment of the Degree of Bachelor of Science at the University of Dar es Salaam. Department of Zoology and Marine Biology, University of Dar es Salaam. 31 pp.

Jaasund, E. (1976) Intertidal seaweeds in Tanzania: A field guide. Dar es Salaam. University of Tromso' $159 \mathrm{pp}$.

Josiah, M.F.R. (1997) Increasing urban population and health risks in Tanzania: A case study of squatters in Dar es Salaam Region. A dissertation submitted for partial fulfillment of the requirement for the degree of Master of Arts (Demography) of the University of Dar es Salaam. Dar es Salaam, Tanzania. $181 \mathrm{pp}$. 
Julius, A. (2005) Physical clean up of Crown-ofThorns Starfish (COTs) in the Dar es Salaam Marine Reserves System. Marine Parks and Reserves Unit, Dar es Salaam. 9 pp.

Kaaya, L.T. (2004) The abundance and diversity of hard corals and associated biota at exposed, semisheltered and sheltered sites on Bongoyo Island Reef. A report submitted in partial fulfilment of the Degree of Bachelor of Science at the University of Dar es Salaam. Department of Zoology and Marine Biology, University of Dar es Salaam. 52 pp.

Kairu, K. \& Nyandwi, N. (eds.) (2000) Guidelines for the study of shoreline change in the western Indian Ocean Region. IOC Manuals and Guides No. 40. United Nations Educational, Scientific and Cultural Organization, Paris. 55 pp.

Kayombo, N.A. (1988) Ecology and fishery of gastropods and other molluscan species along the Dar es Salaam coast. In: Mainoya, J.R. (ed.) Proceedings of the Workshop on Ecology and Bio-productivity of the Marine Coastal Waters of Eastern Africa, 18-20 January 1988, Dar es Salaam. Faculty of Science, University of Dar es Salaam, Tanzania. pp.59-65.

Kinondoni Integrated Coastal Area Management Program. (2001) Program inception report. Kinondoni Integrated Management Program, Dar es Salaam. 27 pp.

Kinondoni Municipal Council. (2003) Kinondoni Integrated Coastal Area Management Program (KICAMP): Phase II Project Proposal. Kinondoni Municipal Council, Dar es Salaam. 27 pp.

Lindén, O. (1993) Resolution on integrated coastal management in Eastern Africa signed in Arusha, Tanzania. Ambio 22(6).

Machiwa, J.F. (1992) Anthropogenic pollution in Dar es Salaam harbor area, Tanzania. Mar. Pollut. Bull. 24(11): 562-567.

Machiwa, J.F. (2000) Heavy metals and organic pollutants in sediments of Dar es Salaam harbour prior to dredging in 1999. Tanz. J. Sci. 26: 2945.

Machumu, E. M. (1996) Comparison between mangrove stand communities at Mtoni Kijichi and Kunduchi creeks. A third year project report submitted in partial fulfilliment for the Degree of Bachelor of Science, at the University of Dar es Salaam. 29 pp.

Makota, V. \& Sallema, R. 2003. Shoreline change: Case study of Kunduchi shores. In: Tanzania State of the Coast Report 2003: The National ICM Strategy and Prospects for Poverty Reduction. Tanzania Coastal Management Partnership (TCMP), Dar es Salaam: 21-24.

Mashauri, D.A. \& Mayo, A. (1990) The environmental impact of industrial and domestic waste water in
Dar es Salaam. In: Khan, M.R. \& Gijzen, H.J. (eds.) Symposium on Environmental Pollution and its Management in Eastern Africa, 11-14 September 1989, Dar es Salaam. Faculty of Science, University of Dar es Salaam. pp. 90101.

McClanahan, T.R., Muthiga, N.A., Kamukuru, A.T., Machano, H. \& Kiambo, R.W. (1999) The effects of marine parks and fishing on coral reefs of northern Tanzania. Biol. Cons. 89: 161-182.

Mchome, M.L. (2002) Characterization of the benthic lifeforms, substrate and invertebrates on the northern side of Kendwa Island. A report submitted in partial fulfilment of the Degree of Bachelor of Science at the University of Dar es Salaam. Department of Zoology and Marine Biology, University of Dar es Salaam. 29 pp.

Mgaya, Y.D. \& Juma, S. (2001) Integrated coastal zone management in Tanzania. In: Voabil, C. \& Engdahl, S. (eds.) The Voyage from Seychelles to Maputo: Success and Failures of Integrated Coastal Zone Management in Eastern Africa and Island States, 1996-2001, Volume 1: Eastern African Mainland Country and Regional Reports. SEACAM. $181 \mathrm{pp}$.

Mgaya, Y.D., Machiwa. J.F., Lugomela, C., Lyimo, T., Joseph, C., Muzuka, A., Shaghude, Y., Mvungi, A., Mapunda, B. \& Mwanuzi, F.L. (2004) Environmental studies of Mtoni mangrove ecosystem, Dar es Salaam. Final report submitted to the Faculty of Science, University of Dar es Salaam, Dar es Salaam. 123 pp.

Mgaya, Y.D., Mwamsojo, G.U.J, Lema, R., Sobo, F.A.S., Kimaro, S. \& others. (2001). Tanzania Mariculture Guidelines Source Book. TCMP/URI. 206 pp.

Mlay, A.P. (2000) Ecology of the intertidal zone of selected sandy/muddy shores in the Dar es Salaam area. M.Sc. thesis, University of Dar es Salaam. $172 \mathrm{pp}$.

Moffat, D., Ngoile, M., Linden, O. \& Francis, J. (1998) The reality of the stomach: Coastal management at the local level in eastern Africa. Ambio 27(8): 590-598

Mohammed, M.S., Muhando, C.A. \& Machano, H. (2000) Assessment of coral reef degradation in Tanzania: results of coral reef monitoring - 1999 . Coral Reef Degradation in the Indian Ocean (CORDIO) and Institute of Marine Sciences, Zanzibar, Tanzania. 20 pp.

Mrema, W.S. (2001) Coral transplanting and assessment of benthic cover on Pangavini Island reef. A report submitted in partial fulfilment of the Degree of Bachelor of Science at the University of Dar es Salaam. Department of Zoology and Marine Biology, University of Dar es Salaam. 37 pp. 
Mremi, S.D. \& Machiwa, J.F. (2003) Heavy metal contamination of mangrove sediments and the associated biota in Dar es Salaam, Tanzania. Tanz. J. Sci. 29(1): 61-75.

Muhando, C.A. (1999) Assessment of the extent of damage, socio-economic effects, mitigation and recovery in Tanzania. In: Linden, O. \& Sporrong, N. (eds.) Coral reef degradation in the Indian Ocean: status reports and project presentations 1999. CORDIO, SAREC Marine Science Program, Stockholm. pp. 43-47.

Munissi, J.E. (2000) Dissolved oxygen, biochemical oxygen demand and selected green algae as indicators of marine pollution near Dar es Salaam. A report submitted in partial fulfilment of the Degree of Bachelor of Science at the University of Dar es Salaam. Department of Zoology and Marine Biology, University of Dar es Salaam. 18 pp.

Mushala, H. M. (1978) Coastal processes along Kunduchi Beach. Journal of the Geographical Association of Tanzania 17: 41-73.

Mwaigomole, S. (2001) Seagrass and macrofauna abundance at Mbweni fish landing site in comparison with an adjacent undisturbed area. A report submitted in partial fulfilment of the Degree of Bachelor of Science at the University of Dar es Salaam. Department of Zoology and Marine Biology, University of Dar es Salaam. 33 pp.

Mwaiseje, B. (1973) Some aspects of the ecology of sandy/muddy intertidal zone in Dar es Salaam area. M.Sc. thesis, University of Dar es Salaam. $103 \mathrm{pp}$.

Nderumaki, M.A. (2004) Assessment of effectiveness of restoration projects in mangrove forests of Mbweni and Bagamoyo, Tanzania. M.Sc. dissertation, University of Dar es Salaam. 75 pp.

Okera, W. (1971) Plankton analysis relative to the feeding habits of Sardinella in Dar es Salaam waters. Ph.D. thesis, University of Dar es Salaam. $212 \mathrm{pp}$.

Organisation for Economic Co-operation and Development. (1993) OCED core set of indicators for environmental performance reviews. OECD Environment Monographs No. 83. OCED, Paris. $39 \mathrm{pp}$.

Pearson, M.P. (1988) Coral reef resources in the Dar es Salaam area. In: Investigations Related to the Protection and Conservation of Coastal Marine Resources in the Dar es Salaam Area. National Environment Management Council, Dar es Salaam. pp. 12-35.

Peter, R. (2002) Characterization of the landward side of Fungu Yasin patch reef and the survival and growth rates of coral transplants. A report submitted in partial fulfilment of the Degree of
Bachelor of Science at the University of Dar es Salaam. Department of Zoology and Marine Biology, University of Dar es Salaam. 48 pp.

Roxburgh, T., Morton, I., Rumisha, C. \& Francis, J. (eds.) (2002) An assessment of the stakeholders and resource use in Dar es Salaam Marine Reserve System. ICRAN/WIOMSA. 102 pp.

Ruitenbeek, J., Hewawasam, I. \& Ngoile, M. (2005) Blueprint 2050: Sustaining the Marine Environment in Mainland Tanzania and Zanzibar. The World Bank, Washington. 125 pp.

Sallema, A.E. (2003) Mangrove species distribution, abundance and restoration potential in Dege Mangrove Ecosystem, Dar es Salaam. M.Sc. dissertation, University of Dar es Salaam. 88 pp.

Semesi, A.K. (1991) Management Plan for the Mangrove ecosystem of Mainland Tanzania. Vol. 11: Mangrove Management Plan for All Coastal Districts. Ministry of Tourism, Natural Resources and Environment, Forest and Beekeeping Division, Catchment Forest Project, Dar es Salaam.

Semesi, A.K. \& Shushu, D. (1988) A survey of seagrasses and seaweeds along the Dar es Salaam coast. In: Investigations Related to the Protection and Conservation of Coastal Marine Resources in Dar es Salaam Area. NEMC/UDSM/IMS/TAFIRI/ Fisheries Division: 36-62.

Talbot, F. \& Wilkinson, C. (2001) Coral reefs, mangroves and seagrassess: a sourcebook for managers. Australian Institute of Marine Science, Townsville. 193 pp.

Tanzania Bureau of Statistics. (2002) The 2002 Population Census of Tanzania. Government Printers, Dar es Salaam.

UNEP. (1989) Coastal and environmental problems of the United Republic of Tanzania. UNEP Regional Seas Reports and Studies, No. $106+$ Annexes I-X.

UNEP. (2006) Country environmental profile information system. UNEP. http://countryprofiles. unep.org/profiles/ER/profile/state-of-theenvironment

United Republic of Tanzania. (1992) Dar es Salaam Sustainable Project. City Council, Dar es Salaam.

United Republic of Tanzania. (2003a) Guidelines for coastal tourism development in Tanzania. Tanzania Coastal Management Partnership, Dar es Salaam. 58 pp.

United Republic of Tanzania. (2003b) National Integrated Coastal Environment Management Strategy. Vice President's Office, United Republic of Tanzania, Dar es Salaam. 52 pp.

United Republic of Tanzania. (2005) The Environmental Management Act, 2004. United Republic of Tanzania, Dar es Salaam. 
Wagner, G.M. (1998) Impact of fishing (including dynamite fishing) on coral reefs. In: Johnstone, R.W., Francis, J. \& Muhando, C.A. (eds.) Coral reefs: Values, threats, and solutions. Proceedings of the national conference on coral reefs, 2-4 December 1997, Zanzibar, Tanzania. Institute of Marine Sciences (University of Dar es Salaam), Zanzibar, Tanzania. pp. 38-44.

Wagner, G.M. (1999) Coral reefs: importance, threats, conservation and restoration. In: Howell, K.M. \& Semesi, A.K. (eds.) Coastal resources of Bagamoyo District, Tanzania. Proceedings of a workshop on coastal resources of Bagamoyo, 18-19 December 1997, Bagamoyo. Faculty of Science, University of Dar es Salaam, Dar es Salaam, Tanzania: pp. 27-32.

Wagner, G.M. (2002). Synthesis of information on the marine environment of Kunduchi and Mbweni. Kinondoni Integrated Coastal Area Management Program (KICAMP), Dar es Salaam. 38 pp.

Wagner, G.M. (2004a) Coral reefs and their management in Tanzania. Western Indian Ocean Journal of Marine Science 3(2): 227-243.

Wagner, G.M. (2004b) Monitoring of coastal and marine resources: Lessons learned. Presented at KICAMP Planning Workshop on Coastal and Marine Resources, Bagamoyo, 10-12 August 2004. Kinondoni Integrated Coastal Area Management Program, Dar es Salaam. 8 pp.

Wagner, G.M. (2005) Participatory monitoring of changes in coastal and marine biodiversity. Indian Journal of Marine Sciences 34(1): 136-146.

Wagner, G.M., Akwilapo, F.D., Mrosso, S., Ulomi, S. \& Masinde, R. (2004) Assessment of Marine Biodiversity, Ecosystem Health and Resource
Status in Mangrove Forests in Mnazi Bay-Ruvuma Estuary Marine Park. IUCN Eastern Africa Programme, Nairobi. 106 pp.

Wagner, G.M., Mallya, U., Juma, S., Mgaya, Y.D., Wahure, O., Mahika, G. \& Wagner, S.M. (1999) A preliminary investigation for an integrated, community-based approach to conservation and restoration on marine ecosystems along the Dar es Salaam coast. African Development Foundation, Dar es Salaam, Tanzania. 124 pp.

Wagner, G.M., Mgaya, Y.D., Akwilapo, F.D., Ngowo, R.G., Sekadende, B.C., Allen, A., Price, N., Zollet, E.A. \& Mackentley, N. (2001) Restoration of coral reef and mangrove ecosystems at Kunduchi and Mbweni, Dar es Salaam, with community participation. In: Richmond, M.D. \& Francis, J. (eds.) Marine science development in Tanzania and eastern Africa. Proceedings of the $20^{\text {th }}$ anniversary conference on advances in marine sciences in Tanzania, 28 June - 1 July 1999, Zanzibar, Tanzania. Institute of Marine Sciences (University of Dar es Salaam) and Western Indian Ocean Marine Science Association (WIOMSA), Zanzibar, Tanzania. pp. 467-488.

Wang, Y.Q., Ngusaru, A., Tobey, J., Makota, V., Bonynge, G., Nugranad, J., Traber, M., Hale, L. \& Bowen, R. (2002) Remote sensing of mangrove change along the Tanzania coast. Marine Geodesy 26(1-2): 1-14.

Wilkinson, C. (Ed.) (2004) Status of coral reefs of the world: 2004. Australian Institute of Marine Science, Townsville. 557 pp.

WWF. (2005) Rufiji-Mafia-Kilwa (RUMAKI) Seascape Programme (2004-2009). WWF Tanzania Programme Office, Dar es Salaam. 76 pp. 